\title{
'Facing Uncharted Waters': Challenges experienced by Occupational Therapy Students undertaking Role-emerging Placements
}

\author{
Channine Clarke \\ University of Brighton, United Kingdom \\ Marion Martin \\ University of Brighton, United Kingdom \\ Gaynor Sadlo \\ University of Brighton, United Kingdom \\ Richard de-Visser \\ University of Sussex, United Kingdom
}

\begin{abstract}
Role-emerging placements, which take place in settings where there are no on-site occupational therapy educators, are increasingly being used within occupational therapy curricula internationally. Although literature on such placements is increasing, little has explored the early stages and demands of such placements. Interpretative phenomenological analysis was used to gain an understanding of how five MSc pre-registration occupational therapy students experienced and ascribed meaning to their role-emerging placements. Interviews were carried out with the students within one month of their role-emerging placement. This article explores one of the themes that emerged from the study, 'Thrown in', that reflected the challenges students faced in the early days of their placement. Key findings revealed that students found the early stages of placement cognitively, emotionally and ontologically demanding. They felt temporarily lost, anxious and overwhelmed by their experience, which impacted on their sense of self. Recommendation is made that consideration is given to students' ontological discomfort, or 'sense of being' on placement and pre-placement preparation.
\end{abstract}

Keywords: occupational therapy; placement challenges; role-emerging placements

\section{Introduction}

Role-emerging placements, 'which occur at a site where there is not an established occupational therapist role' (College of Occupational Therapists 2006:1), are increasingly being advocated to help prepare students for more autonomous and diverse practices (Thew et al. 2011, Dancza et al. 2013, Clarke et al. 2014a, Clarke et al. 2015). However, whilst the literature on role-emerging placements is increasing, it tends to focus on how they have been implemented in British universities (Wood 2005, Hook and Kenny 2007, Thew, Hargreaves, and Cronin-Davis 2008), to present a rationale for their development (Fortune, Farnworth, and McKinstry 2006, Cooper and Raine 2009, Rodger et al. 2007), or reflect the opinions of educators and placement tutors about their effectiveness (Wood 2005, Wilcock, Sledding, and Kershaw 2009). Only a small number of papers seek to understand students' experiences in any detail, for example Bossers et al. (1997), Totten and Pratt (2001), Fieldhouse and Fedden (2009) and Dancza et al.(2013). 
As the lead author is a placement tutor, there was a need to understand the meaning that role-emerging placements had for students in order to have the confidence to use them within the curriculum. The research question was, therefore:

\section{What are occupational therapy students' experiences of role-emerging placements?}

This article presents one of the themes, 'Thrown in', that was identified as part of this larger study and reflects the challenges faced by students in the early stages of their placement (Clarke 2012). All emerging themes are shown in Appendix 1. Other findings, which focus more on the positive end outcome for the students, are discussed in separate papers (Clarke et al. 2014a, Clarke et al. 2015).

\section{Literature Review}

Critical appraisal of the literature highlights that various methods have been used to evaluate the effectiveness of role-emerging placements; predominantly questionnaires, rating scales, verbal reports, focus groups, nominal group technique and placement de-briefing sessions (James and Prigg 2004, Gilbert Hunt 2006, Hook and Kenney 2007, Thew, Hargreaves, and Cronin-Davis 2008, Rodger et al. 2009). Whilst these provide a useful overview of issues associated with such placements, in-depth exploration of students' personal experiences is often limited (Overton et al. 2009, Clarke et al. 2014b).

Despite an increase in anecdotal student reports, these tend to focus on the practicalities of carrying out the placement or how they promoted occupational therapy rather than revealing data that allows a deeper understanding of the personal meanings students ascribed to their placement. Furthermore, as such articles appear to have been published to try and promote role-emerging placements, they often favour the positive aspects of the placement, making it difficult to gain an understanding of any potential challenges, limitations or associated risks.

Both international and UK literature highlights various benefits of role-emerging placements, including professional and personal growth and development, increased confidence in team working, resource and time management, use of supervision, communication skills and evidence based practice (Bossers et al. 1997, Huddleston 1999, Prigg and Mackenzie 2002, James and Prigg 2004, Gilbert Hunt 2006, Thew, Hargreaves, and Cronin-Davis 2008, Edwards and Thew 2011, Clarke et al. 2014a). Other literature suggests that role-emerging placements may be the most significant learning experience that students have in preparing them for practice (Alsop and Donald 1996, Fieldhouse and Fedden 2009, Clarke et al. 2014a). Conversely, authors have highlighted placement limitations such as difficulties establishing professional identity, compromising clinical experiences, disadvantaging weaker students and different expectations of students' on-site and off-site supervisors (Fisher and Savin-Baden 2002, Wood 2005, Hook and Kenney 2007, Cooper and Raine 2009, Thomas and Roger 2011, Kirke, Layton, and Sim 2007, Thew, Hargreaves, and Cronin-Davis 2008). Whilst much of the early literature tends to be opinion based regarding potential benefits (Westmorland and Jung 1997, Bilics, Lamothe, and Murphy 2002, Banks and Head 2004), and also argues that role-emerging placements are a good way to address the shortage of traditional placements (Healy 2005, Sadlo and Craik 2005), there appears to be a developing interest in this topic and, as such, there are an increasing number of research based papers, particularly arising from placement tutors (Soloman and Jung 2006, Thew, Hargreaves, and Cronin-Davis 2008, Warren et al. 2013, Clarke et al. 2014a, and Clarke et al. 2015). Whilst some authors have used qualitative approaches to gain deeper understandings of students' experiences, not all are explicit about the methodological framework or methods of analysis, making it difficult to assess rigour and trustworthiness.

One of the gaps evident in the literature is exploration of students' experiences of the challenges they encounter on these placements. This article seeks to help address this by highlighting the cognitive, physical and emotional demands of such placements experienced by five occupational therapy students. 


\section{Methodology}

Interpretative phenomenological analysis (IPA) (Smith et al. 2009), underpinned by hermeneutic phenomenology, was the methodology for the study. IPA aims to understand a person's lived experience of particular phenomena as they are situated within the world around them and, as such, was considered appropriate for the study which sought to understand students' placement experiences.

\section{Participants}

Following ethical approval by the University's Research Ethics and Governance Committee, five female occupational therapy students who had chosen a final year, role-emerging placement consented to take part. As a placement tutor, the author had access to students who had organised these placements. Ethical consideration needed to be given to issues of power and coercion, and so students were recruited from the accelerated Masters programme as the author did not teach on that programme and was not involved with placement allocation for these students. It was made clear in all information and consent sheets that participation was voluntary and would not affect participating students' education.

Participants were all students on an MSc pre-registration programme and they were all mature students. This sample size was congruent with IPA guidelines, allowing for a deeper and more meaningful idiographic level of analysis (Smith et al. 2009). The student placements were working with refugees, a children's charity, a forensic community team, a homeless service and a drugs and alcohol rehabilitation team.

\section{Data collection and analysis}

Semi-structured interviews were used to gather detailed accounts of students' experiences after their placements, a method that Smith et al. (2009) advocate as the most effective form of data collection in facilitating a rich understanding of a person's individual experiences. Interviews, of up to 90 minutes, began with a broad question designed to encourage participants to talk freely about their placements. Prompts were then used to help focus on specific experiences; for example, first day, a difficult day, memorable moments.

Data analysis followed IPA guidelines (Smith et al. 2009); allowing themes to emerge from the participants' own words. Each transcript was analysed individually, with the researcher making notes in the left-hand margin of key words used by the participant, and interpretations, thoughts, ideas of the researcher in the right hand margin. These key words were then clustered together, which allowed concepts to emerge (e.g. autonomy, identity). Once each transcript had been analysed, concepts were explored across participants to look for commonalities and divergences in experience, and were clustered again to create subthemes and then higher order themes. An audit trail was kept of all stages of analysis. Verbatim quotes were used to illustrate the researcher's interpretations. Summaries of each student's transcript, with the researcher's interpretations and themes, were shared with each participant, who stated they agreed with the interpretations.

\section{Rigour}

As suggested by Yardley (2008), all decisions made were justified and followed IPA guidelines, showing 'rigour' and 'transparency'. Detailed consideration was given to the 'coherence' of the study, ensuing congruence between research question, methodology and methods. Quotes show the reader how themes reflect both individual and shared experiences and provide a plausible and convincing argument. Theme titles also reflect participants' own words to help maintain the phenomenological stance. As suggested by Shaw (2010), a reflexive journal was kept to help analyse the way in which the researcher's assumptions and pre-understandings influenced the study. 


\section{Findings}

As shown in Appendix 1, the whole study resulted in five overarching themes. Other papers discuss findings of other themes (Clarke et al. 2014a, Clarke et al. 2015). It was felt important to present this particular theme as a separate paper as there is a paucity of literature that explores in any detail the challenges experienced by students on these placements.

\section{Thrown in}

In the majority of cases, the first half of the student's placement was physically, cognitively and emotionally demanding. There was a sense that students had felt 'thrown' into the placement, going in alone without any additional preparation, which led them to become temporarily lost, anxious and overwhelmed as they struggled with issues of professional isolation, lack of professional identity, matching expectations with those of the team and increased responsibility. This led to feelings of vulnerability, pressure, confusion and selfdoubt, all of which impacted on students' sense of self. The theme is divided into two subthemes (Table 1).

Student names are pseudonyms.

Table 1. Master Theme: Thrown in

\begin{tabular}{|c|c|}
\hline \multicolumn{2}{|l|}{ Thrown in } \\
\hline Sub-themes & Concepts \\
\hline Going it alone & $\begin{array}{l}\text { Uncharted waters } \\
\text { Out there on my own }\end{array}$ \\
\hline Facing the challenges & $\begin{array}{l}\text { Need to sing from the same hymn sheet } \\
\text { Responsibility on my shoulders } \\
\text { The emotional toll }\end{array}$ \\
\hline
\end{tabular}

\section{Sub-theme: Going it alone}

This sub-theme reflects the students' sense of isolation as they ventured into unfamiliar territory.

\section{- Uncharted waters}

This concept concerns the fear that arose for the majority of the students as a result of being in new and unfamiliar environments. None of them had previously been into or tested out the settings and had no idea what these were going to be like. This was highlighted by Ella's use of the phrase 'uncharted waters':

it frightened me $[\ldots]$ I was in uncharted waters sort of thing.

Each placement that a student does is in a new setting and, as such, some anxiety may have been expected. However, the students appeared to experience a more intense reaction to their role-emerging placement, conveyed in words such as 'frightened' (Ella), 'scary' (Sophie), 'terrified' (Jayne), and 'daunted' (Poppy). This appeared to be closely linked to the selfdirected nature of the placement, feelings of professional isolation, and uncertainty about their role, as discussed in the following concepts.

\section{- Out there on my own}


Although they had chosen their placements knowing that there was no occupational therapy service in place, once the placement started four of the five students quickly felt the absence of the profession. This was summarised by Ella who, despite being surrounded by other professionals, felt 'thrown in', a metaphor that appeared to reflect students' sense of isolation and vulnerability:

I really am out there on my own, that would be the only thing I would say, I felt a little bit out there on my own and thrown in, you know.

Although they had a weekly off-site occupational therapy educator, the students missed having a professional practice educator on-site to help provide structure and deal with the pragmatic and therapeutic questions that arose. Sophie's extract spoke for many of the others, highlighting their anxiety, isolation and uncertainty:

I was quite anxious really 'cause I think not having any OT direction really and knowing that I was very much on my own, lots of questions like 'What is my timetable going to be like?', 'How am I going to document what I am doing?', those kind of practical things I was quite, you know, anxious about.

Students reflected back on previous placements where the occupational therapy department had provided a sense of familiarity, reassurance and structure. These were cultural aspects of previous placements that appeared to give them a sense of belonging, comfort and security and were clearly missed. Jayne, for example, appeared to feel implicitly understood on past placements and valued the support and guidance that other therapists provided:

at first it felt kind of difficult, erm, because you're used to working in a team where there are OT's so they know where you're coming from all the time so you don't necessarily have to explain what you're doing so much or you kind of get ideas from them, you're bouncing ideas off each other.

This previous dependence on the team was also recognised by Poppy, who, following an assessment, realised that she did not know what to do next:

it made me realize how much you rely on the OT departments that are already set up and that was, I suppose, probably quite a pivotal moment [...] I sat here with all this information and that was when I suppose it hit me, it was like, because normally, you know, you might know that they might do cooking or they might do a skills learning or they might recommend they join this group or, but I just didn't have any of that and I was like well, great, but now what do I do with it? So I had this kind of moment.

Here, Poppy appeared to have been 'hit' by the recognition that she was on her own and that there were aspects of occupational therapy that she did not know. This significant 'moment' appeared to take place when she was reflecting on how to 'be' an occupational therapist, something that may not have been facilitated if her supervisor had been present or she had simply been 'doing' or copying what was already in place.

Despite professional supervision, it appeared that the students felt isolated by their sense that no-one really understood what it was like to be doing the placement. Poppy stated that she would have 'liked someone from the university to have actually seen where I was on placement and the challenges that I faced'. Similarly, Sophie felt that her professional supervisor was not fully able to understand what the placement was like for her:

it is very different and you know even talking to my OT educator about it, she knew, obviously what I was getting on with, but not fully, you know, she couldn't meet the clients with me and she couldn't meet the staff with me, so it was, it was, yeah it was just strange, I think, just different from other placements in that sense, not having someone physically there with me from my profession. 
Poppy and Ella's sense of isolation was enhanced by the lack of practical resources. Ella highlighted how she had tried to prepare herself by surrounding herself with assessments and resources at the start of the placement, almost like a security blanket. As well as providing Ella with a familiar structure, it could be argued that they made her feel less vulnerable, providing a practical as well as psychological link to the profession:

I was very much on my own and I made, in the beginning, of just grabbing all the MOHO [Model of Human Occupation] assessments, grabbing everything I could so I had a folder of whatever I might need 'cause I couldn't ask my educator (CPN) 'what do you think about this?' although I did, I sounded stuff out with her but it's very different to having your profession around you and that network to draw upon. I didn't have that and as a novice I felt that.

In addition to perhaps providing a psychological security blanket, it could be suggested that having a familiar model of practice, and assessment tools, helped Ella to make sense of the placement. In the absence of an on-site occupational therapist, these familiar tools may have helped guide her thinking about occupational needs and possible occupation-focused interventions, making links between theory and practice for herself.

In contrast to other students, Sally did not experience feelings of professional isolation:

I never felt that actually. They [placement staff] were always so responsive to [...] to what I talked about and to what, you know, to my explanations of OT. I never felt isolated, ever, I always felt very welcomed, very supported, um [...] and you know, I saw people getting enthusiastic about what I was doing which is, you know, always amazing. I had my supervisor just down the road if I did need her help, um [...] but no, I never felt that isolation.

It would appear that, for Sally, a sense of belonging existed from the start and prevented the feelings of isolation experienced by the others. She suggests, throughout her transcript, that this is mainly due to the team's interest in occupational therapy, the support and encouragement she received from the staff, and her internal motivation to take on this type of placement.

\section{Sub-theme: Facing the challenges}

This sub-theme reflects the students' struggle with role conflict, meeting the expectations of the team, and their concern about the increased levels of responsibility as the lone 'occupational therapist'.

\section{- Need to sing from the same hymn sheet}

One of the challenges all the students faced was matching their own placement expectations with those of the team. Whilst students primarily saw the focus of their placement as promoting a wider occupational perspective, some teams wanted them to work on particular projects. This left many of them experiencing role conflict, fearful of the mismatch in expectations and, perhaps due to the pressure of wanting to appear competent, trying to do it all:

before I went, I think, from speaking to staff here, it was to look at the service as a whole, so that's what I kind of went in thinking, and then I realized that actually there was cases that people wanted me to work on, so then I thought I needed to do that as well, erm, so maybe I should have done one or the other but I sort of tried to do both (Poppy).

The start of her placement was also an 'uncomfortable time' for Sophie, who had a clear idea about the type of role she wanted to carry out but this did not match that of her manager. Having been 'invited to do the placement', Sophie wanted to please the team and make a good impression, but at the same time knew that there were things she wanted to achieve which would mean turning down the team's requests. Sophie spoke of her need to ensure 
that 'everybody was singing from the same hymn sheet', a metaphor that signified the importance for her of the team knowing what to expect of her. This was similar to a 'same page' metaphor used by Sally, who was also anxious about a possible mismatch of role expectations with her manager. It is possible that Poppy, Sophie and Sally's desire for clarity was enhanced by the fact they were being assessed. They may have felt vulnerable to failure where confusion existed, and clarity would have been important in providing them with the security and direction they felt they needed to pass the placement.

Poppy was also concerned about the high expectations that her team had of her. These expectations resulted in her being asked to assist with high risk cases for which she felt inexperienced and unprepared. When reflecting on a home-visit that she had assisted with, she stated she would 'like to have gone as a student', a statement that indicated she had not been viewed as a student or indeed that she herself had adopted the student role, a position that led to her feeling vulnerable:

I think it's just feeling vulnerable as they came to me as an OT professional [...] and I didn't feel like I'm an OT professional yet.

Similar to Poppy, Sophie and Ella found themselves in situations that they felt were above their level of competency. The concerns that this raised for them in relation to risk are discussed in the following sub-theme, as this was closely linked to levels of responsibility.

\section{- Responsibility on my shoulders}

One of the biggest challenges highlighted was the increased responsibility that came with being an autonomous student. This was in contrast to previous traditional placements where direction had been provided and students had not had to worry about taking as much responsibility for their own learning:

I remember thinking it was very different from first days of going into OT placements because you're told what you will be doing, whereas this they were asking me what I would be doing [...] so I think that was quite a big difference for me 'cause usually you go in and it's sort of 'this will be where you sit and this will be what you will be doing', whereas this didn't have any of that.

Here, Poppy appeared to have become aware of a shift in power dynamics between herself and her educator. She had moved from a more passive role on previous placements (being directed by the supervisor) to a more active role where she now had to take control of her own learning. Recognition of this role reversal was also made explicit by Sophie:

there were lots of things that maybe I, I felt that you know I was maybe the one that was directing quite a lot of the time and in a traditional setting maybe would have been directed from somebody else, from my OT educator, so I was having to take on that role of making sure those things were done, really.

There was a close link between this concept of responsibility and that of matching expectations. Sophie, Ella and Poppy for example, recalled instances where they had been asked to work on cases that they felt were above their level of competency and voiced concern about the level of responsibility they had. This highlights an issue of risk where the students felt under pressure to carry out a role for which they were not confident (or qualified). On reflection, students recognised that they had been aware that the levels of responsibility were too high but felt a level of compliance was necessary in order to pass their placements. This was made explicit by Ella, who stated 'I needed to pass so I had to do it', and Poppy, who stated she 'went along with it' and subsequently found herself 'getting carried away with it all'.

Students also felt an increased responsibility to represent the profession. Sophie and Ella referred to themselves as the 'face of OT' and an 'ambassador', metaphors that reflected the responsibility they felt as the person solely responsible for how the profession was represented and perceived. This was exacerbated by the students' lack of confidence about 
their professional identity and role. Poppy, for example, recalled her early inability to communicate clearly to others what occupational therapy was but remembered thinking that by this stage of the course she should have had a better understanding. It was not until faced with the demand of having to think about and articulate her professional identity that Poppy realised this was something she was unable to do:

I sort of gave a garbled message of what I thought OT was and they sort of said 'What will you be doing here?' and I just remember thinking that was hard because I wasn't really sure yet.

This suggested that having to explain or reflect on her identity at a deeper level was not something Poppy had previously done on placement. This previous level of passivity was also confirmed by others:

I don't remember having to do it on the traditional placements. Um [...] and I think because the OT role had been um [...] developed for quite a long time in all the other placements, um [...] years and years and years l'd imagine [...] it was something that um [...] you know, didn't have to be made [...] made clear (Jayne).

In addition to the high levels of responsibility felt by these students, they also experienced other strong emotions, as highlighted in the following sub-theme.

\section{- The emotional toll}

The challenges that some students had to face at the start of the placement left them feeling overwhelmed. This led them to question their judgment, ability to cope, and choice of placement:

It just felt, felt very overwhelming and yeah there were a couple of days that week when I thought 'this is too much, what have I done?' (Sophie)

For Jayne the emotional impact of the placement was particularly difficult, and she spoke explicitly about her initial dislike, and at times 'hatred', of the placement, which led her to question her sense of self. Where she had previously thought she would cope well with the placement, she now questioned whether she was good enough:

I started, actually didn't like it at first I must say, the first few weeks l'd say, not just the first week, the first three weeks, I was really doubting whether I could do it or not, whether I actually liked it, whether I was good enough to do it, whether I was going to get through it. It was all quite negative.

All the students spoke of the emotional demand of working with clients who had distressing stories and backgrounds. It took time to adjust to hearing these stories, and Sophie suggested that they may have been more emotionally challenging due to the setting, where for her the clients were more 'real': seeing clients in their own homes and in the community compared to institutional, hospital based environments.

When faced with particularly anxiety-provoking situations, some students appeared to present an emotional façade to hide their true feelings. Jayne spoke of how she felt she had to talk to clients even though she was 'dying inside through nerves and fear'. Similarly, Ella highlighted the conflict between her external persona (presenting a sense of bravado) and her inner feelings of insecurity. This suggested that there was an inauthenticity of self that resulted from a need to cover their true feelings:

when I'm in fear, and this is the truth, when I started the placement I thought, 'oh this is a bit scary', I come across as being super confident, sometimes you wouldn't know, I'll come in with 'yes I'm ready to go', 'twenty on my caseload that's great'. 
In summary, these findings highlight the challenges experienced by five occupational therapy students in the early stages of their role-emerging placements. The following discussion considers possible reasons behind these experiences, the relationship of the findings to existing literature, and makes recommendations for practice and education.

\section{Discussion and implications for practice}

As the students ventured into the uncharted waters of their placements, their sense of self took a distinctive turn, with many of them appearing lost, confused and anxious. They appeared to feel out of their depth and lacked confidence in themselves to meet the challenges of the placement, a finding similar to existing studies where students experienced a sense of culture shock (Prigg and Mackenzie 2002, James and Prigg 2004, Fieldhouse and Fedden 2009). When faced with the unfamiliar placement environment, students questioned what they and the profession had to offer and struggled with the challenges that this presented to their perception of self, professional role and identity.

Such findings suggest that the students' 'sense of being' had been displaced by a strange and challenging learning environment. Their experiences appeared to reflect the 'ontological discomfort' described by Barnett (2007: 76). They became confused and overwhelmed, wanting to continue with the placement but becoming struck by the realisation that they did not have a clear sense of self, purpose, role or direction. Their struggle with what they could offer and who they were as occupational therapy students appeared similar to the 'fragmentation' that Thomas and Rodger (2011: 46) suggest occurs on role-emerging placements when a student's identity is challenged by an unfamiliar environment.

The notion of disjuncture (Jarvis 2010) also appears relevant where students grappled with feelings of apprehension, uncertainty and self-doubt as a result of encountering new and unfamiliar experiences rather than routine and taken-for-granted practices. They could no longer rely on others or familiar structures to guide them, and the impact of going it alone was felt at an emotional, cognitive and practical level. The students had to deal with negative feelings about themselves and the placement, ask questions of themselves, their knowledge and understandings, and find their own meaningful ways forward. They had to look within themselves to bring forth their own coping strategies, reasoning and voice (Barnett 2007), a position that appeared to lead to high levels of anxiety but at the same time facilitated development of their own professional ways of being (Clarke et al. 2014a, Clarke et al. 2015). Although one student (Sally) did not express the same level of anxiety about being on her own (attributed by her to the willingness of the team to embrace occupational therapy and their interest in what she was doing), she did experience similar anxieties and challenges related to expectations and responsibility and appeared to go through the same ontological questioning.

The students recognised how reliant they had been in the past on the culture of a traditional occupational therapy department. This could be likened to the 'occupational therapy bubble' described by Fieldhouse and Fedden (2009:306), whereby existing departmental philosophies, assessments, interventions and team support provide students with a sense of purpose, direction and support. It was not until they experienced the lack of a familiar community of practice (Lave and Wenger 2003) that they realised how important these had been and the sense of security and identity they provided. This would appear to reflect Heidegger's phenomenolgical notion that tasks and routine practices are often carried out in a model of 'average everydayness' (Wisnewski 2013: 33), and it is not until these practices are absent or altered that one becomes aware of their significance. It is therefore important that educators on both traditional and non-traditional placements encourage students to become much more critically aware of their identity and role and to develop their own autonomous thinking.

Students' anxiety was exacerbated by their feelings that their off-site educator did not understand the setting and their need to match their expectations with those of their teams. This is consistent with findings of existing studies that identify this as one of the main causes 
of student stress on role-emerging placements and from which useful recommendations have been made (Fisher and Savin-Baden 2002, James and Prigg 2004, Mulholland and Derdall 2005, Thew, Hargreaves, and Cronin-Davis 2008, Edwards and Thew 2011, Thomas and Rodger 2011). In addition to these recommendations, off-site educators and visiting tutors are encouraged to spend time in the setting to become familiar with the environment that the student is working in, enabling students to feel more supported.

A particular concern raised in this study was the pressure some students felt to work on cases perceived to be above their competency level. Whilst reference has been made in the literature to the possible risks of role-emerging placements, the potential vulnerability of students and clients as a result of this particular pressure is not something that appears to have been addressed. The moral dilemmas that students appear to face and the responsibility they feel to be seen as competent students would suggest that taking on tasks outside their competency level would seem to be an inherent risk of such placements in the absence of on-site occupational therapists who, as suggested by Hook and Kenney (2007), often shelter students from conflict and risk on traditional placements. This clearly needs to be highlighted to students and supervisors in pre-placement sessions and become a focus in weekly supervision.

The façade of competence that the students in this study presented could be likened to the 'professional face' that Sweeney, Webley, and Treacher (2001: 384) suggest occupational therapy supervisees often use to safeguard their sense of professional competence, although their study was carried out with qualified therapists rather than students. Evans et al. (2010), however, suggest that students are reluctant to discuss problems or anxieties for fear of disapproval and that learners seek to create workplace identities that present themselves in a positive light as trustworthy and competent individuals. This has implications for practice where educators and students need to develop relationships that allow students to become more authentic in their way of being and to voice anxieties without fear of reprisal. Whilst the issue of risk clearly needs to be addressed, there is also a fine balance to be struck between sheltering students from difficult situations and allowing them to take positive risks in order to further their development. As Barnett (2007: 145) suggests, without positive risk-taking, students are not afforded the space to develop either 'intellectually, practically or in their own being'.

Whilst the early stages of the placement were a difficult time for the majority of students, later placement experiences indicated that their discomfort was perhaps necessary in order to facilitate a deeper level of learning and to come into their new self (Clarke et al. 2014a). Such anxiety and discomfort could therefore be considered a necessary and enlightening event as they moved forward into a new authentic way of being. This is supported by Barnett (2007), who suggests that emotionally challenging pedagogic situations should not be avoided in higher education but instead need to be created in order to move students into a new place and prepare them for future turbulent professional journeys. It is for these reasons, and based on the findings of this study, that with careful planning, role-emerging placements have been made compulsory at the University of Brighton.

\section{Limitations of the study}

Based on the experiences of five female students from one university, findings cannot be considered representative of other students. Findings are likely to be influenced by specific placement contexts and other settings may reveal different experiences. These placements were elective, and as such, consideration needs to be given to how students who have not made the choice to do such a placement may deal with such experiences. The interviews were reliant on participants' memories, and richer insights may have been elicited if interviews had been carried out during the placements. 


\section{Key implications for practice}

- It is suggested that role-emerging placements should be compulsory for all students. Whilst some students may find this more challenging than others, findings suggest that all students, with support and preparation, should be given the opportunity to experience the benefits such placements appear to offer.

- Universities have a clear role to play in clarifying with students and educators their roles, responsibilities and expectations in order that students are not placed in situations, or adopt roles, that are above their level of competency. Where possible, on and off-site educators should meet with each other and the student at the start of the placement to clarify roles and expectations. Off-site educators should also become as familiar as possible with the setting in order to give them some insight into the environment in which the student will be working and possible challenges that the student will be facing.

- Whilst findings support existing recommendations that pre-placement sessions for students are important (Overton 2009, Thomas and Rodger 2011, Thew et al. 2011), they indicate that these need to be combined with longer periods of induction in order to help address the levels of anxiety, uncertainty, expectations and professional isolation experienced by those in this study. An extended induction period, for example, the one-day-a-week-for-five-weeks option suggested by Thew, Hargreaves, and Cronin-Davis (2008), has subsequently been used by the University of Brighton and found to be effective in allowing students to familiarise themselves with the setting, reflect on the aims of the service, and consider their role and possible interventions before starting the placement full-time. As part of this induction period, action learning sets (ALS) with peers and university tutors have been used, and are recommended, to encourage students' critical reflection, self-awareness and understandings of practice as well as providing a forum to discuss practical concerns. It is suggested that this longer induction period and time for critical reflection, along with half way visits from tutors and placement blogs, provide strategies that support students towards successful placement outcomes and reduce some of the challenges expressed in this study.

- Feelings of isolation and anxiety may be reduced by students undertaking roleemerging placements in pairs. This recommendation is supported by literature that advocates peer-learning and support on placement (Martin et al. 2004, Soloman and Jung 2006, Mackenzie et al. 2007, Thomas and Rodger 2011). However, further study needs to explore the impact of peer-learning on role-emerging placements.

\section{Further research}

Further research is required to explore the value of role-emerging placements. This may include:

- Further phenomenological studies to establish whether similar themes emerge. Weekly reflective journals may provide deeper insights into student's experiences, capturing data as it occurs rather than relying on post-placement reflections. Ethnographic studies would allow exploration of the impact of the placement culture on the students' experiences.

- To date, no studies have been carried out that have explored the experiences of 'academically weaker' students. This area of exploration would allow a deeper understanding of the extent to which academic ability impacts on placement learning outcomes and provide recommendations for placement tutors who may need to consider additional support for these students. 
- No studies have evaluated or compared models of role-emerging placements. Studies could therefore consider the benefits and limitations of models such as peer learning and interdisciplinary role-emerging placements.

- There is a current gap in literature that explores the experiences of the occupational therapy and on-site educator. Research also needs to determine the impact of the student on the organisation and service user outcomes as a result of occupationfocused interventions.

\section{Conclusion}

Whilst previous authors have indicated that students face a number of challenges on roleemerging placements, in-depth consideration of these is largely absent in the literature. This article has added to the existing literature by highlighting the cognitive and emotional demands of such placements for five MSc occupational therapy students. It suggests that the challenges experienced by these students were more profound due to absence of on-site occupational therapy educators and issues of risk, and the way in which students and educators are prepared for and supported on such placements need to be carefully considered. However, the findings indicate that such challenges present opportunities for the enhancement of students' understandings of self and the profession, and as such are an important part of the role-emerging placement experience. 


\section{References}

Alsop, A., Donald, M. (1996) Making the most of fieldwork education: a practical approach. London: Chapman Hall

Banks, S. and Head, B. (2004) 'Partnering Occupational Therapy and Community Development'. Canadian Journal of Occupational Therapy 71 (1), 5-8

Barnett, R. (2007) A Will to Learn. Maidenhead: Open University Press, McGraw Hill.

Bilics, A.R., Lamothe, H. and Murphy, C. (2002) 'The Community Practicum: an Opportunity to Synthesise Learning for Emerging Practices'. Occupational Therapy in Healthcare $16,69-73$.

Bossers, A., Cook, J., Polatajko, H. and Laine, C. (1997) 'Understanding the Role-emerging Fieldwork Placement'. Canadian Journal of Occupational Therapy 64 (1), 70-81

Clarke, C. (2012) Occupational Therapy Students' Experiences of Role-emerging Placements and their Influence on Professional Practice. Unpublished PhD Thesis. Brighton: University of Brighton

Clarke, C., Martin, M., Sadlo, G., de-Visser, R. (2014a) 'The Development on an Authentic Professional Identify on Role-emerging Placements'. British Journal of Occupational Therapy 77 (5), 222-229

Clarke, C., de-Visser, R., Martin, M., Sadlo, G. (2014b) 'Role-emerging Placements: a Useful Model for Occupational Therapy Practice Education? A Review of the Literature'. International Journal of Practice-based Learning in Health and Social Care 2 (2), 1426

Clarke, C., Martin, M., de-Visser, R., Sadlo, G. (2015) 'Sustaining Professional Identity in Practice Following Role-emerging Placements'. British Journal of Occupational Therapy 78 (1), $42-50$

College of Occupational Therapists (2006) Developing the Occupational Therapy Profession: Providing New Work-based Learning Opportunities for Students. London: COT

Cooper, R. and Raine, R. (2009) 'Role-emerging Placements are an Essential Risk for the Development of the Occupational Therapy Profession: the Debate'. British Journal of Occupational Therapy 72 (9), 416-418

Dancza, K., Warren, A., Copley, J., Rodger, S., Moran, M., Mckay, E. and Taylor, A. (2013) 'Learning Experiences on Role-emerging Placements: An Exploration from the Students' Perspective. Australian Occupational Therapy Journal 60 (6), 427-435

Edwards, M. and Thew, M. (2011) 'Models of role emerging placements'. in Role Emerging Occupational Therapy. ed. by Thew,M. Edwards, M. Baptiste, S. and Molineux, M. Chichester: Wiley-Blackwell, 15-35

Evans, N.J., Forney, D.S., Guido, F.M., Patton, L.D. and Renn, K.A. (2010) Student Development in College: Theory, Research and practice. $2^{\text {nd }}$ edn. San Francisco: Jossey-Bass

Fieldhouse, F. and Fedden, T. (2009) 'Exploring the Learning Process on a Role-emerging Practice Placement: a Qualitative Study'. British Journal of Occupational Therapy 72 (7), 302-307

Fisher, A. and Savin-Baden, M. (2002) 'Modernising Fieldwork, Part 2: Realising the Potential'. British Journal of Occupational Therapy 65 (6), 275-282 
Fortune, T., Farnworth, L. and McKinstry, C. (2006) 'Project-focussed Fieldwork: Core Business or Fieldwork Fillers?' Australian Occupational Therapy Journal 53, 233-236

Gilbert Hunt, S. (2006) 'A Practice Placement Education Model Based upon a Primary Health Care Perspective Used in South Australia'. British Journal of Occupational Therapy 69 (2), 81-85

Healy, J. (2005) ‘Practice placements: at breaking point?’. OT News 2, 35

Hook, A. and Kenney, C. (2007) 'Evaluating Role Emerging Placements'. OT News 7, 25

Huddleston, R. (1999) 'Clinical Placements for the Professions Allied to Medicine, Part 1: a Summary'. British Journal of Occupational Therapy62 (5), 213-219

James, C. and Prigg, A. (2004) 'A Self-directed Fieldwork Program to Provide Alternative Occupational Health Placements for Undergraduate Occupational Therapy Students'. Australian Occupational Therapy Journal 51, 60-68

Jarvis, P. (2010) Adult Education and Lifelong Learning, Theory and Practice. 4th edn. Oxon: Routledge

Kirke, P., Layton, N. and Sim, J. (2007) 'Informing Fieldwork Design: Key Elements to Quality in Fieldwork Education for Undergraduate Occupational Therapy Students'. Australian Occupational Therapy Journal54, 13-22

Lave, J. and Wenger, E. (2003) Situated Learning: Legitimate Peripheral Participation. Cambridge: Cambridge University Press

Mackenzie, A., Craik, C., Tempest, S., Cordingly, K., Buckingham, I. and Hale, S. (2007) 'Interprofessional Learning in Practice'. British Journal of Occupational Therapy 70 (8), 358-361

Martin, M., Morris, J., Moore A., Sadlo, G. and Crouch, V. (2004) 'Evaluating Practice Education Models in Occupational Therapy: Comparing 1:1, 2:1 and 3:1 Placements'. British Journal of Occupational Therapy 67 (5), 192-200

Mulholland, S. and Derdall, M. (2005) 'A Strategy for Supervising Occupational Therapy Students at Community Sites'. Occupational Therapy International 12 (1), 28-43

Overton A, Clarke M, Thomas Y (2009) 'A Review of Non-traditional Occupational Therapy Practice Placement Education: a Focus on Role-emerging and Project Placements'. British Journal of Occupational Therapy 72 (7), 294-301

Prigg, A. and Mackenzie, L. (2002) 'Project Placements for Undergraduate Occupational Therapy Students: Design, Implementation and Evaluation'. Occupational Therapy International 9 (3), 210-236

Rodger, S., Thomas, Y., Dickson, D., McBryde, C., Broadbridge, J., Hawkins, R and Edwards, A. (2007) 'Putting Students to Work: Valuing Fieldwork Placements as a Mechanism for Recruitment and Shaping the Future Occupational Therapy Workforce'. Australian Occupational Therapy Journa54, 94-97

Rodger, S., Thomas, Y., Holley, S., Springfield, E., Broadbridge, J., Greber, C., Mcbryde, C., Hawkins, R., Banks, R. (2009) 'Increasing the Occupational Therapy Mental Health Workforce through Innovative Practice Education: Evaluation of an Innovative Practice Education Placement Trial in Mental Health'. Australian Occupational Therapy Journal 56 (6), 409-417

Sadlo, G. and Craik, C. (2005) 'Time for Creative Action'. OT News 3, 22 
Shaw, R. (2010) Embedding Reflexivity Within Experiential Qualitative Psychology. Qualitative Research in Psychology 7, 233-243

Smith, J.A., Flowers, P. and Larkin, M. (2009) Interpretative Phenomenological Analysis. London: SAGE Publications Ltd.

Soloman, P. and Jung, B. (2006) 'An Interprofessional Role-emerging Placement in HIV Rehabilitation'. International Journal of Therapy and Rehabilitation 13 (2), 59-64

Sweeney, G., Webley, P. and Treacher, A. (2001) 'Supervision in Occupational Therapy, Part 2: the Supervisee's Dilemma'. British Journal of Occupational Therapy 64 (8), 380386

Thew, M., Hargreaves, A. and Cronin-Davis, J. (2008) 'An Evaluation of Role-emerging Practice Placement Model for a Full Cohort of Occupational Therapy Students'. British Journal of Occupational Therapy 71 (8), 348-353

Thew, M., Edwards, M., Baptiste, S. and Molineux, M. (2011) Role Emerging Occupational Therapy. Maximising Occupation-Focused Practice. Chichester: Wiley-Blackwell

Thomas, Y. and Rodger, S. (2011) Successful Role Emerging Placements: It is all in the Preparation. In Role Emerging Occupational Therapy ed. by Thew, M. Edwards, M. Baptiste,S. and Molineux, M. Chichester: Wiley-Blackwell, 39-53

Totten, C. and Pratt, J. (2001) 'Innovation in Fieldwork Education: Working with Members of the Homeless Population in Glasgow'. British Journal of Occupational Therapy 64 (11), 559-563

Warren, A., Dancza, K., McKay, E., Taylor, A., Moran, M., Rodger, S. and Copely, J. (2013) Supervising Role-emerging Placements: Creating Opportunities for Innovation. Australian Occupational Therapy Journal 60 no. s1, 1-50

Westmorland, M.J. and Jung, B. (1997) 'Educational Partnerships: Student and Faculty Involvement'. British Journal of Therapy and Rehabilitation 4 (12), 671-675

Wilcock, J., Sledding, F. and Kershaw, A. (2009) 'Role-emerging Placements: the Educators' Experience'. OT News 9, 24

Wisnewski, J.J. (2013) Heidegger: An Introduction. Plymouth: Rowman and Littlefield Publishers

Wood, A. (2005) 'Student Practice Contexts: Changing Face, Changing Place'. British Journal of Occupational Therapy 68 (8), 375-378

Yardley, L. (2008) Demonstrating Validity in Qualitative Psychology. In Qualitative Psychology: a Practical Guide to Research Methods. $2^{\text {nd }}$ edn. ed. by Smith, J.A.. London: SAGE Publications Ltd., 235-251 
Appendix 1: Table of themes for whole study (Clarke 2012)

\begin{tabular}{|c|c|c|}
\hline Master Theme & Sub-theme & Concepts \\
\hline \multirow[t]{2}{*}{$\begin{array}{l}\text { 1. Not a run of the mill } \\
\text { placement }\end{array}$} & 1.1 Outside the box & $\begin{array}{l}\text { 1.1.1 Testing themselves out } \\
\text { 1.1.2 Standing apart from other } \\
\text { students } \\
\text { 1.1.3 Promoting OT in new } \\
\text { settings }\end{array}$ \\
\hline & 1.2 In two minds & $\begin{array}{l}\text { 1.2.1 Excitement vs } \\
\text { apprehension }\end{array}$ \\
\hline \multirow[t]{2}{*}{ 2. Thrown in } & 2.1 Going it alone & $\begin{array}{l}\text { 2.1.1 Uncharted waters } \\
\text { 2.1.2 Out there on my own }\end{array}$ \\
\hline & 2.2 Facing the challenges & $\begin{array}{l}\text { 2.2.1 Need to sing from the } \\
\text { same hymn sheet } \\
\text { 2.2.2 Responsibility on my } \\
\text { shoulders } \\
\text { 2.2.3 The emotional toll }\end{array}$ \\
\hline \multirow[t]{2}{*}{ 3. Finding a way forward } & 3.1. Drawing on inner resources & $\begin{array}{l}\text { 3.1.1 A certain type of student } \\
\text { 3.1.2 making sense of the } \\
\text { experience }\end{array}$ \\
\hline & 3.2 Being part of a team & $\begin{array}{l}\text { 3.2.1 Sense of belonging } \\
\text { 3.2.2 Having that support } \\
\text { 3.2.3 Learning through doing }\end{array}$ \\
\hline \multirow[t]{3}{*}{ 4. Awareness of change } & 4.1 Development of 'new' self & $\begin{array}{l}\text { 4.1.1 Emerging from the } \\
\text { shadows } \\
\text { 4.1.2 Growing up } \\
\text { 4.1.3 Belief in self }\end{array}$ \\
\hline & $\begin{array}{l}\text { 4.2 Re-appraisal of the } \\
\text { profession }\end{array}$ & $\begin{array}{l}\text { 4.2.1 Having a deeper belief in } \\
\text { the profession } \\
\text { 4.2.2 Seeing clients in a different } \\
\text { light }\end{array}$ \\
\hline & 4.3 Making a difference & $\begin{array}{l}\text { 4.3.1 Seeing that smile } \\
\text { 4.3.2 Leaving a legacy }\end{array}$ \\
\hline \multirow[t]{2}{*}{ 5. 'Being' in the real world } & 5.1 Standing on my own two feet & $\begin{array}{l}\text { 5.1.1 Gaining employment } \\
\text { 5.1.2 Confidence for practice }\end{array}$ \\
\hline & $\begin{array}{l}5.2 \text { 'Being' an occupational } \\
\text { therapist }\end{array}$ & $\begin{array}{l}\text { 5.2.1 Real life } \\
\text { 5.2.2 Consolidation of identity } \\
\text { 5.2.3 Challenge to identity } \\
\text { 5.2.4 looking to the future }\end{array}$ \\
\hline
\end{tabular}

